\title{
O Programa UNI no Brasil: uma avaliação da coerência no seu processo de formulação e implementação
}

\author{
Auristela Maciel Lins 1 \\ Luiz Carlos de Oliveira Cecílio 2
}

LINS, A.M., CECÍLIO, L.C.O. The UNI Program in Brazil: an evaluation of the coherence of its development and implementation processes. Interface - Comunicação, Saúde, Educação, v. 2, n.3, 1998

This study assessed the coherence of the set of ideas behind the UNI Program, over three projects in Brazil, analyzing the relationship between Purposes, Methods, and Organization, in the light of Mario Testa's coherence postulate. The empirical material on which this paper was based consisted of bibliography on the UNI Program and interviews with twelve key individuals, "actors" who helped shape the process. These were classified into three groups: UNI Program Formulators, UNI Project Directors, and Evaluators. The data were edited, systematized and analyzed according to both analytical categories (determination, conditioning, collective subject and paradigm) and empirical categories (purpose, method and organization). The analysis evidenced an idealized view of the true context within which the Projects are made operational. Furthermore, it identified dialectically constructed lines of determination and conditioning, within the actual scenario of the actors, and in the relationship between subject and object, sometimes in a direction directly contrary to that which had been taken for granted during the formulation of the Program. The investigation also identified shifts towards change in the reality of the UNI Projects, whether at the university or within health and community services. The limitations present both in the theoretical functionalistic frame of reference adopted during the initial structuring of the Program, and in the limited importance granted to the lines of conditioning or determination that organizations issue, may be considered as the explanation for the Program's failure to attain full efficacy.

KEY WORDS: Public Health- Evaluation; Community- Development; Community - University.

O estudo avaliou a coerência do ideário do Programa UNI, em três projetos no Brasil, analisando a relação entre Propósitos, Métodos e Organização, à luz do Postulado de Coerência de Mario Testa. Bibliografia sobre o Programa UNI e entrevistas com doze atores do seu processo, agrupados como Formuladores do Programa UNI, Diretores de Projetos UNI e Avaliadores, compuseram o material empírico. Este foi recortado, sistematizado e analisado segundo categorias analíticas de determinação, condicionamento, sujeito coletivo e paradigma e segundo categorias empíricas de propósito, método e organização. Evidenciou-se uma formulação idealizada do espaço real de operacionalização dos Projetos e a presença de linhas de determinação e condicionamento construídas,

dialeticamente, no espaço concreto de atuação dos atores e na relação entre sujeito e objeto, algumas vezes, em sentido contrário ao que previamente se supôs na formulação do Programa. A investigação conseguiu identificar movimentos de mudanças nas realidades dos Projetos UNI, tanto na universidade, como nos serviços de saúde e comunidade. As limitações presentes no referencial teórico funcionalista, adotado na formulação inicial do Programa e na pouca valorização dada às linhas de condicionamento ou determinação que partem das organizações podem ser apontadas como explicações para o não alcance de sua eficácia plena.

PALAVRAS-CHAVE: Saúde Pública-Avaliação; Comunidade-Desenvolvimento; Comunidade - Universidade.

\footnotetext{
${ }^{1}$ Avaliadora do Projeto UNI de Botucatu, médica sanitarista do Centro de Saúde Escola da Faculdade de Medicina de Botucatu, Universidade Estadual Paulista - Unesp.E-mail: auri@botunet.com.br.

${ }_{2}$ Docente do Departamento de Medicina Preventiva e Social. Faculdade de Ciências Médicas, Universidade Estadual de Campinas Unicamp.
} 


\section{Introdução}

A Fundação W. K. Kellogg, enquanto organização financiadora de projetos, tem tido uma inserção muito importante nos países da América Latina, desde a década de quarenta. Tem financiado inúmeros projetos vinculados ao ensino das profissões médicas e à área da saúde, entre outros, constituindo-se, portanto, como objeto de estudo obrigatório para quem tem como preocupações investigativas o campo da Saúde Coletiva.

Um de seus mais recentes programas para a América Latina (início da década de 90) é o Programa UNI, um conjunto de 20 projetos espalhados por países da região, sendo seis deles no Brasil. Denominado Uma Nova Iniciativa na Educação dos Profissionais do Setor de Saúde, o programa UNI propõe uma mudança de paradigma na educação desses profissionais a partir, principalmente, da crítica ao modelo flexneriano de formação médica $e$ aos projetos sociais que propunham modelos que isolavam três setores fundamentais na promoção de uma melhor qualidade de vida para as comunidades. Nesse sentido, a universidade, os serviços de saúde e os movimentos organizados da comunidade deveriam atuar em conjunto na formação dos profissionais de saúde, levando-os para ambientes de ensino/ aprendizagem diferentes do hospital, nos quais classicamente são formados, ambientes esses mais próximos da comunidade. O objetivo seria proporcionar-lhes um processo de ensino/aprendizagem construído de forma multidisciplinar, exercido em caráter multiprofissional e voltado para as necessidades dessas comunidades, oferecendo contribuição na construção de sistemas de saúde mais acessíveis e acolhedores e favorecer $o$ fortalecimento da organização dos movimentos comunitários em saúde. $\mathrm{O}$ novo paradigma proposto é, portanto, centrado na parceria entre as organizações envolvidas e as existentes dentro delas próprias.

A pesquisa que ora apresentamos teve a preocupação de avaliar a própria concepção do Programa UNI, em seus pressupostos teóricometodológicos, e verificar sua potencial eficácia enquanto proposta de intervenção sobre a realidade, analisando a coerência de seu ideário entre Propósitos, Métodos e Organização, à luz do Postulado de Coerência de Mario Testa.

Utilizamos o conceito de avaliação formulado por Scriven (Worthen et al., 1997) que define avaliar como julgar valor e mérito do objeto da avaliação, porém considerando, como Fetterman (1997), que valor e mérito não são estáticos e que não devem ser seu objetivo final, e sim, parte do processo.

Segundo Testa (1992), deve existir uma necessária relação de coerência entre os propósitos de governo (ou de um programa), os métodos utilizados para implementá-los e as organizações onde deverão ser operacionalizados. Essa relação de coerência é dada, em ciências sociais, pela determinação e pelo condicionamento, sendo a primeira, uma força positiva que estabelece limites dentro dos quais um fenômeno deve ocorrer $e$ a segunda, uma força negativa que fixa limites fora dos quais um fenômeno não pode ocorrer.

Testa afirma que a não observância dessa relação de coerência pode levar à falência do projeto. Essa idéia perseguiu o desenvolvimento da pesquisa, na 
qual procuramos estabelecer se a coerência dada no momento da formulação do Programa UNI concretizou-se nos espaços dos projetos durante sua operacionalização e quais seus efeitos sobre o Programa.

O material empírico da pesquisa compôs-se de bibliografias sobre o Programa UNI, seu ideário, propostas e avaliação e por entrevistas com doze atores de seu processo, selecionados dentre o staff da representação da Fundação W. K. Kellogg no Brasil e dentre os Projetos UNI de Botucatu, Brasília e Londrina. Esses entrevistados foram, posteriormente, agrupados como Formuladores do Programa UNI, Diretores de Projetos UNI, sendo um ex-diretor e três atuais diretores, e Avaliadores, sendo dois da equipe de avaliadores do Cluster e dois avaliadores de projetos. O material foi recortado, sistematizado $e$ analisado segundo algumas categorias analíticas emprestadas do Postulado de Coerência e outras que consideramos importantes: determinação, condicionamento, sujeito coletivo e paradigma, e segundo as categorias empíricas de propósito, método (parceria e participação comunitária) e organização.

\section{O postulado de coerência modificado}

Para Testa (1992) existem dois níveis de determinação e condicionamento. Um mais interno, representado pela relação entre proposta, método $e$ organização. Outro mais externo que, além de determinar o primeiro, também apresenta linhas de determinação e condicionamento entre seus componentes: o Papel do Estado, a Teoria e a História. Para Testa, o papel do Estado determina seus propósitos; a teoria sobre o problema determina o método com o qual se pretende resolvê-lo e a história determina as organizações da sociedade.

No nível mais interno, as relações se dão no sentido da determinação dos propósitos para os métodos; dos propósitos para as organizações e do método sobre a organização. Por outro lado, os métodos condicionariam os propósitos e ambos seriam condicionados pela organização (figura 1).

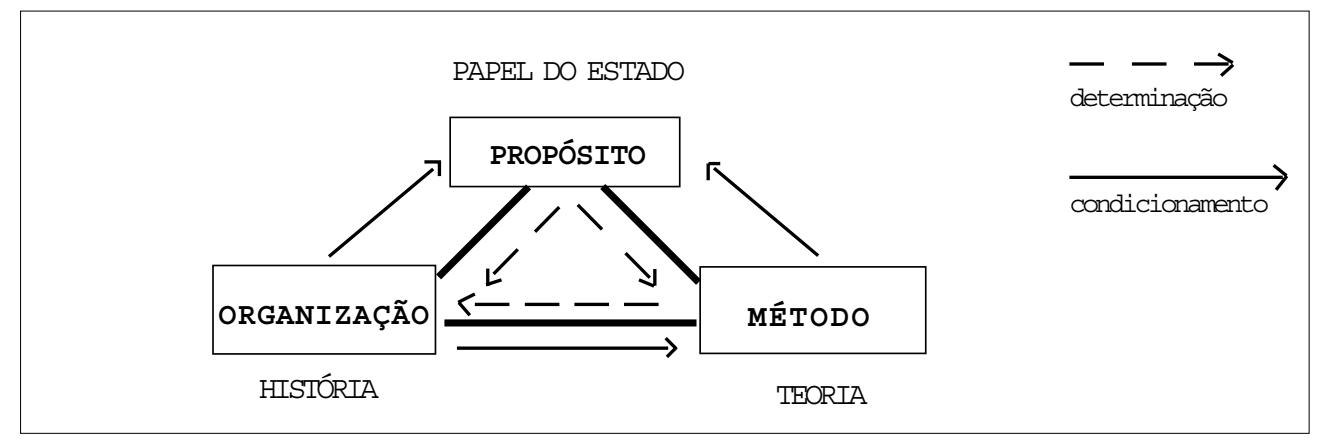

Figura 1 - Postulado de Coerência de Mario Testa. (Fonte: LINS, 1997)

Promovendo um recorte no Postulado de Coerência e fundamentados nas categorias determinação e condicionamento aí presentes, usamos esses conceitos, aceitos por Testa ao formular seu postulado, e tomamos o 
conceito de paradigma encontrado em Gilles (1993, p.264): "na ciência, padrão, teoria explicativa de processos ou de fenômenos" para criar um esquema analítico na tentativa de verificar a coerência do Programa UNI, como foi formulado e como tem sido implementado $e$ avaliado.

No que concerne à relação de determinação entre os componentes de segundo para o primeiro nível, mantivemos a Teoria (ou Paradigma) como categoria presente porque acreditamos que a teoria é peça fundamental no Programa UNI. É ela quem, por assim dizer, "comanda" o ciclo de determinações e condicionamentos (figura 2).

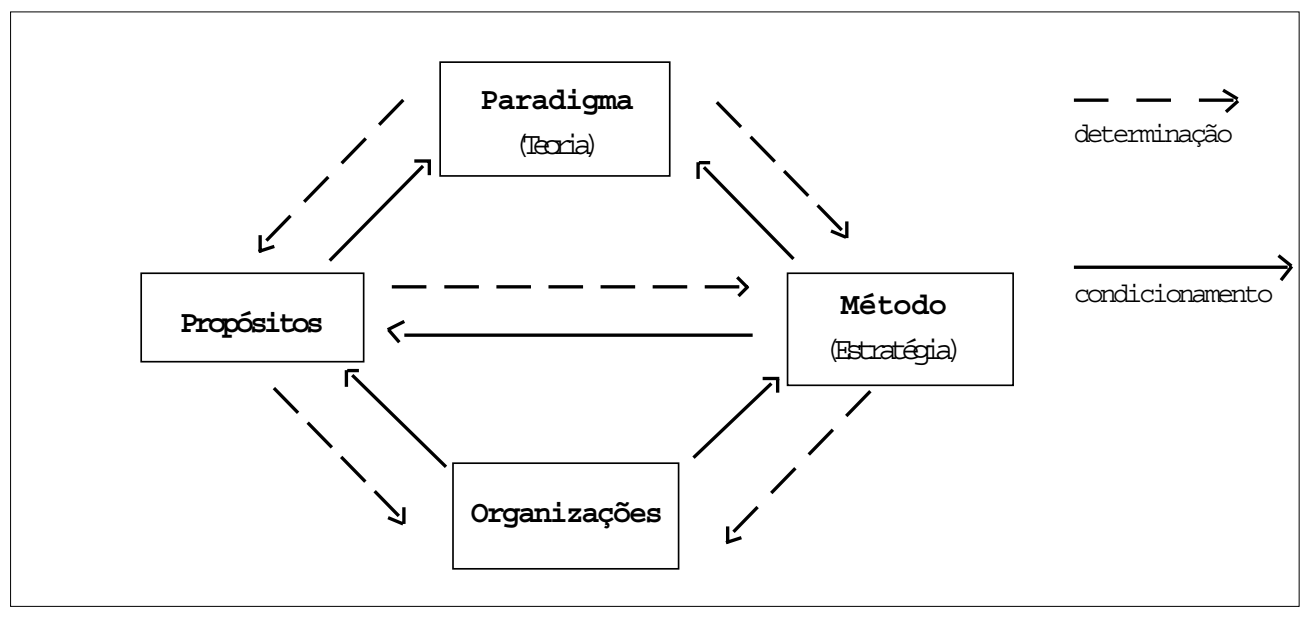

Figura 2 - Postulado de Coerência Modificado. (Fonte: LTNS, 1997)

A teoria utilizada pelo Programa UNI para explicar as condições de vida das populações nos países da América Latina é herdeira de tradições sócioculturais e religiosas da organização que lhe deu origem, a Fundação W. K. Kellogg e das inúmeras experiências de programas e projetos irmãos desenvolvidos em países da América Latina. Assim, ela propõe integrar os diversos setores - formação de profissionais de saúde, prestação de assistência à saúde e comunidade - ao pensar um novo paradigma para o setor social (Figura 3). Acreditamos que, na visão dos formuladores do Programa UNI, esse paradigma determinava seus propósitos e as estratégias pensadas e utilizadas para atingi-los, porque as organizações são sobredeterminadas por propósitos e métodos.

Uma proposta como a do UNI, que tenta desenvolver um trabalho em parceria entre três distintos atores ou sujeitos coletivos como a academia, os serviços de saúde e a comunidade organizada, é mediada por diversos interesses e objetivos comuns, mas é também, e principalmente, atravessada por conflitos cognitivos, conflitos de interesses e por relações de poder. Daí usarmos o conceito de Sujeito Coletivo conforme presente em Sader (1991): “...uma coletividade onde se elabora uma identidade e se organizam práticas através das quais seus membros pretendem defender seus interesses e expressar suas vontades, constituindo-se nessa luta", que comporta os conceitos de conflito e poder. 
As categorias empíricas Propósito, Método e Organização surgiram junto com a reflexão acerca do Postulado de Coerência como referencial teórico e foram sendo mais qualificadas com as repetidas leituras do material bibliográfico e das entrevistas. Assim, propósito e método são vistos conforme Ferreira (1991): "algo que se pretende fazer ou conseguir; projeto ou fim a que se visa", "caminho para chegar a um fim" $e$ organização, como formulado por Baremblitt (1996, p.235), "conjuntos de formas materiais que põem em efetividade as opções que as instituições distribuem, que as instituições enunciam".

\section{Teoria, propósito, método e organização no Programa UNI}

\section{Teoria no Programa UNI}

Como podemos visualizar na Figura 3, a Fundação Kellogg e o Programa UNI partem da afirmação da inadequação dos modelos de formação de profissionais, de assistência e de participação comunitária, para explicar as insatisfatórias condições de saúde e de vida da população latino-americana.

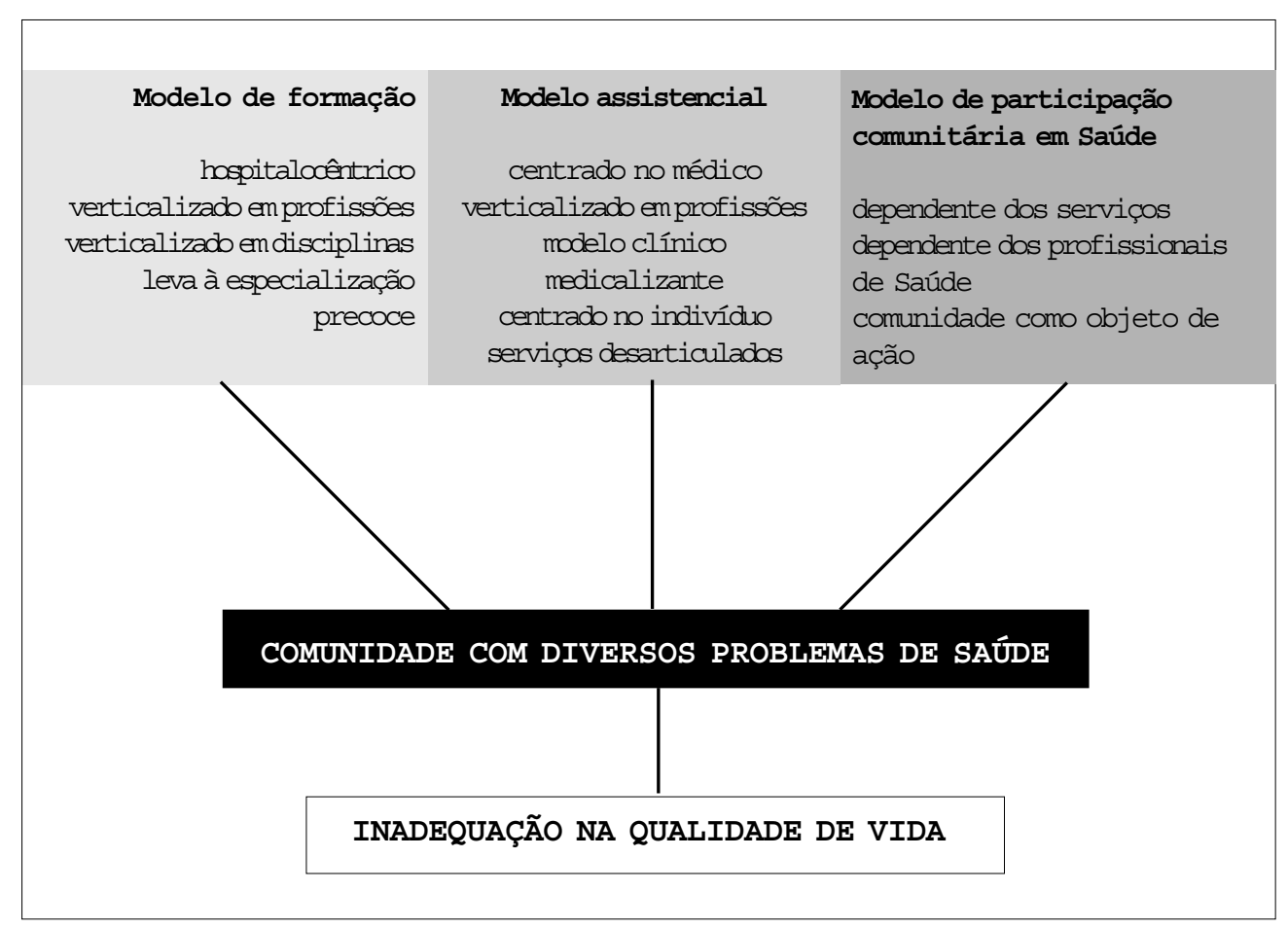

Figura 3 - Estrutura geral do modelo explicativo do Programa UNI para as condições de vida da população

Na perspectiva da Fundação Kellogg, os indivíduos e os grupos têm potência para conduzir transformações em suas condições concretas de vida e de saúde, desde que utilizem adequadamente o conhecimento e os recursos existentes. 
Na perspectiva do Programa UNI, há, claramente, uma referência à Teoria de Sistemas como suporte teórico a sua formulação. Outra referência teórica presente na fala dos atores formuladores do Programa UNI diz respeito a aspectos advindos da corrente fenomenológica, que postula aos pequenos grupos como: associações de moradores, conselhos de saúde, associações profissionais, à própria família e aos grupos participantes dos Projetos, a responsabilidade por sua identificação enquanto grupo, por sua estabilidade (Minayo, 1993, p. 58) e a do próprio sistema, em última instância.

Ao afirmarmos a vinculação do Programa UNI à corrente funcionalista, perpassada por alguns princípios fenomenológicos, não tivemos a pretensão de expressar um juízo de valor maniqueísta tipo "bom ou ruim". Quisemos tão-somente analisar a potência explicativa da teoria que fundamenta os propósitos, métodos e organizações eleitos pelo Programa UNI.

$\mathrm{O}$ uso de concepções funcionalistas como instrumental de análise de contextos complexos e pouco estruturados, como os espaços concretos dos Projetos UNI, levou a uma idealização dos mesmos, não considerando os conflitos de interesses e até antagonismos presentes entre os diferentes grupos nesses espaços.

\section{Propósito no Programa UNI}

Nos grupos de formuladores e gerentes de Projetos há, em geral, regularidades presentes em seus enunciados. O grupo de formuladores parece apontar para a melhoria da qualidade de vida da população como propósito final do Programa UNI, vindo o desenvolvimento de modelos na formação, assistência e desenvolvimento comunitário - como propósitos intermediários (ou produtos) e a parceria entre as três organizações como uma das principais, diríamos a principal, estratégia a ser utilizada.

O grupo de diretores afirma o desenvolvimento do modelo de formação de profissionais de saúde como o propósito final do Programa, transformando-o em um projeto acadêmico, no sentido de que também nomeiam como propósitos intermediários produtos internos à universidade: reforma curricular, capacitação pedagógica dos docentes e outros. Nesse sentido, o desenvolvimento dos modelos assistencial e de participação comunitária seriam utilizados como estratégias.

Um terceiro grupo, não tão coeso, composto por atores dos três grupos, nomeia a melhoria do sistema de saúde como propósito final, definindo a formação de recursos humanos e a organização da comunidade como estratégias para atingi-lo.

Já dentre o grupo de avaliadores, encontramos mais diferenças que regularidades, no que se refere a seu imaginário sobre propósito no Programa UNI. Pudemos ver, no entanto, que, apesar das diferenças, este grupo não se atém aos limites de qualquer modelo ao nomear os propósitos. Expressam uma visão de finalidade social mais ampla, mesmo que seja para uma das organizações: a universidade ou o serviço.

As diferenças mais acentuadas, portanto, se dão entre os grupos de formuladores do Programa e os diretores de Projetos UNI. Entre os 
primeiros, o propósito visualizado e esperado é o de transformação mais ampla, transformação social com foco no setor saúde, mas utilizando a formação de pessoal e a participação comunitária como estratégias. Há uma preocupação de superação de experiências anteriores (Projetos IDA) no que elas tiveram de limitante (o isolamento, por exemplo), daí diretrizes como a de "parceria". Entre os diretores de Projetos, o propósito é de transformação do modelo de formação profissional para a saúde, mas o foco é colocado na Universidade, com parcerias, mas aparentemente descolado de um propósito de transformação social mais ampla.

Dessa forma, três distintos grupos estavam conformados - os formuladores, os diretores de Projetos e os avaliadores - com relação às imagens que estabeleceram para os propósitos a serem buscados pelos Projetos ou pelo Programa em última instância. Dois deles apareciam com imagens bem marcantes e um terceiro nem tanto. Apareceram, portanto, três distintos propósitos finais que poderiam ser considerados como complementares, mas que, em sua operacionalização, poderiam ocorrer vieses em conseqüência dos diferentes interesses envolvidos.

É na análise da categoria propósito que melhor aparece o princípio funcionalista de articulação das partes ou dos subsistemas para a recuperação da totalidade social. Em qualquer dos propósitos identificados, assumidos pelos grupos de atores entrevistados, há uma clara referência à necessidade de articular, como em uma engrenagem, sejam as organizações envolvidas, sejam os diversos departamentos ou disciplinas, sejam ainda os estabelecimentos de saúde, ou os diversos grupos no nível da comunidade.

No caso específico dos Projetos UNI, a incorporação, por outros atores, em sua realidade concreta, de outros referenciais mais potentes que o funcionalismo, possibilitou avanços importantes na parceria entre as organizações envolvidas e no seu desenvolvimento.

À luz das categorias analíticas de determinação e condicionamento e no espaço correspondente ao movimento que se dá entre Teoria e Propósito, conforme colocados no Postulado Modificado e no Postulado de Coerência de Testa, podemos afirmar que a teoria explicativa do Programa UNI sobre o processo de disputas, interno aos projetos, pelo menos no momento de sua concepção, sobrevalorizou os conflitos cognitivos em detrimento dos conflitos de interesses dos diferentes grupos, que também têm seus projetos e controlam recursos, o que determinou estratégias insuficientes ou equivocadas para sua operacionalização. Quando confrontados com a realidade dos contextos dos projetos, a teoria passou a ser condicionada pelos propósitos reais dos grupos com mais poder em cada projeto e o paradigma, assim como os objetivos intermediários e finais, foram se modificando e sendo adaptados.

\section{Método no Programa UNI}

Pudemos ver que os princípios colocados pelo Programa UNI no trato com os Projetos, desde que adequadamente gerenciados, colocavam-se como estratégias de conformação dos grupos enquanto sujeitos. O protagonismo ativo (Kisil e Chaves, 1994, p. 5) tem, claramente, uma definição do grupo 
enquanto sujeito do processo.

Há um reconhecimento explícito da presença da categoria poder na relação do grupo condutor e dos líderes com outros grupos e atores nas organizações (Kisil e Chaves, 1994, p. 8), mas há, por outro lado, uma lacuna por conta do não reconhecimento de que os outros atores, outros grupos externos aos Projetos, também manejam recursos de poder e portam outros projetos. A mensagem claramente colocada é a de que o poder que detém o grupo condutor deva ser "distribuído" com os diversos grupos.

Nesse momento de concepção inicial e no que os autores explicitamente referiam enquanto estratégias ou métodos, não há uma abordagem direta às categorias que mencionamos. Elas, porém, estão presentes em diversos outros momentos e documentos do Programa. O próprio título dado ao Programa UNI, "Uma Nova Iniciativa na Educação dos Profissionais de Saúde: União com a Comunidade", já fala de uma das estratégias propostas.

\section{PARCERIA E CONFLITO:}

da concepção idealizada à operacionalização em situação

Um desses documentos de suporte teórico elaborados pela equipe de avaliação do Cluster define assim a parceria:

\footnotetext{
El partneship o parcería es una asociación entre actores diferentes, para el logro de fines comunes; constituye una modalidad de gestión asociada; los vínculos entre los socios se dan en un pie de igualdad o semejanza en la correspondencia y la proporción. Esta modalidad es superadora de los poderes relativos de las partes, se orienta al desarrollo de cada una y al mejoramiento del conjunto. La modalidad de gestión asociada contribuye a la democratización (Programa UNI, 1996, p. 2).
}

A parceria era, desta forma, um meio pelo qual os diferentes grupos ou organizações envolvidos poderiam atingir fins comuns e, segundo seus formuladores, a intenção do Programa UNI era colocá-los em igualdade de condições. A parceria era também entendida como uma característica essencial e definidora dos Projetos UNI (Programa UNI, 1996, p. 3). O reconhecimento do poder relativo das partes interessadas e a expectativa de superá-lo podem ser o reconhecimento da existência da assimetria de poder entre os parceiros, principalmente ao pregar a necessidade de fortalecimento (empowerment) de alguns grupos, mais especificamente de grupos da comunidade, participantes da parceria.

Vimos que os formuladores do Programa traziam, claramente, a idéia de busca de objetivos comuns, ou seja, havia uma ausência explícita da possibilidade da existência de conflitos de interesses na concepção inicial. Para o Entrevistado 3, os conflitos ocorrem por conta dos desvios na formação, desvios esses que podem ser corrigidos pelo próprio sistema formador. O Entrevistado 4 também expressa idéia de funcionalidade, ao traduzir a possibilidade de que, aos poucos, as divergências possam ser convertidas em interesses comuns. 
Já os diretores de Projetos expressam a existência de conflitos de interesses $e$ as dificuldades para encontrar os "interesses comuns". Os avaliadores são muito enfáticos ao afirmarem a existência de contradições internas e externas aos diversos grupos e até a "ingenuidade na concepção de parceria entre iguais". Mesmo o Entrevistado 5, que não vê conflitos no desenho, ou na concepção do Programa, reconhece o surgimento deles durante sua operacionalização nos Projetos.

Essas falas reforçam o pressuposto de que a formulação ou o desenho do Programa idealizava os contextos nos quais ocorreriam os projetos. A operacionalização das idéias fez surgir diferentes conflitos ideológicos e de interesses, o que levou os grupos condutores a promover novos desenhos para propósitos e estratégias. Essa atuação situacional promovida pelos grupos em seus contextos foi provocada pelas relações de poder que permeavam os atores $e$ ou as instituições parceiras do processo, condicionando os propósitos iniciais e até redirecionando ou determinando a conformação de novos propósitos, talvez transformando os propósitos intermediários em finais.

Essa idealização por parte dos formuladores se dá em razão do referencial teórico que embasa o Programa UNI e, em última instância, a própria Fundação W. K. Kellogg. A complementaridade de propósitos entre os diversos atores ou instituições, a idéia de adaptação colocada pelo Entrevistado 4 e a concepção de desvios ou disfunções do aparelho formador colocadas pelo Entrevistado 3 traduzem um referencial funcionalista, permeado por referenciais fenomenológicos (Minayo, 1993) de afirmação da autonomia das pessoas e grupos, que trazem a importância dos significados subjetivos das relações sociais, mas que não pressupõem a existência de necessidades e interesses, também construídos a partir de determinantes históricos e econômicos da sociedade.

$\mathrm{Na}$ análise dos métodos, nos momentos e espaços concretos das organizações nas quais se deu a operacionalização dos propósitos, fervilham as expressões de inadequação dos instrumentais funcionalistas para a realidade dos Projetos UNI. Aí surgem, claramente, as propostas de busca de objetivos comuns "superadores de los poderes relativos de las partes" $e$ orientados "al mejoramiento del conjunto"; neles surgem também as perspectivas de mudanças graduais e progressivas, de forma a serem absorvidas pelo sistema, sem provocar qualquer solução de continuidade. Em contrapartida, é aí que surgem os conflitos com toda sua expressão de pertinência ao contexto e não como desvios que podem ser absorvidos pelas partes ou pela totalidade.

As estratégias de participação comunitária e parceria tomadas por nós como categorias empíricas para melhor aprofundar a análise e sistematização das falas dos atores, dentro da categoria método, foram sendo adaptadas de acordo com a finalidade de cada grupo de sujeitos no processo, mostrando a relação dialética entre o objeto e o método, conforme explicita Campos (apud Silva Júnior, 1996), sobre as contribuições de Mario Testa à formulação do modelo "Em Defesa da Vida" e mostrando a relação sujeito-objeto nas construções e reconstruções do espaço cotidiano.

A concepção da parceria como uma relação de iguais mostrou-se uma 
concepção idealizada. É interessante observar a regularidade presente na fala dos entrevistados no que concerne à reprodução do discurso oficial do Programa UNI - a articulação de diferentes parceiros na busca de objetivos comuns e, em última instância, do bem comum. É um discurso repetido em diversos momentos pelos vários grupos de entrevistados, embora esses expressem uma série de experiências cotidianas que negam essa funcionalidade nas relações concretas.

A parceria entre as três organizações é uma das mais inovadoras concepções e estratégias colocadas pelo ideário e deve ser estimulada, mas não como um instrumento para encobrir as diferenças. A parceria nos UNI é, intrinsecamente, conflituosa. Acreditamos que os conflitos são os desencadeadores do diálogo, devendo para tanto ser "publicizados", não para superar os poderes das partes ou para o melhoramento geral, mas para marcar as diferenças e, mesmo, para aclarar as não-diferenças. Contudo, os atores dos espaços concretos dos Projetos têm utilizado estratégias de conformação de sujeitos, possibilitando o acúmulo de poder por certos grupos.

Porém, qual a direcionalidade da parceria? Com qual finalidade estimular um trabalho conjunto com essas três diferentes organizações? Um dos documentos do Programa que orientam a avaliação de Cluster, ao falar dos propósitos do Programa, diz:

Estimular y apoyar la articulación entre las áreas de educación, servicios y comunidad, para contribuir a la mejoria de las condiciones de salud de la poblacíon y la formación de los professionales de la salud (Programa UNI, 1993, p. 1).

Portanto, a parceria entre as três organizações estava sendo utilizada, na concepção dos seus formuladores, como estratégia para a melhoria das condições de saúde da população e para a melhoria da formação dos profissionais de saúde.

Outros dois documentos, também do Cluster, reforçam esta visão, dois e três anos após o primeiro documento:

(el partnership) constituye una estrategia superadora del poder relativo de las partes interessadas para generar un cambio beneficioso de su propia situación y de la salud y bienestar de sus comunidades (Programa UNI, 1995 e 1996).

Em um documento da avaliação de Cluster (Programa UNI, 1997), parceria é apresentada como

...um dos princípios realmente inovadores do UNI em relação a outras estratégias desenvolvidas para promover mudanças na formação dos profissionais de saúde. (grifo nosso)

Os documentos do Cluster, assim, direcionavam suas lentes para acompanhar, pela parceria, o desempenho dos projetos no sentido de dois 
grandes propósitos: melhoria das condições de saúde da comunidade e melhoria da formação de profissionais de saúde. No documento mais recente, o propósito é reduzido para um, a promoção de mudanças na formação dos profissionais de saúde. Perguntamos: nessa afirmação, o segundo propósito está implícito? Melhorar a formação dos profissionais de saúde leva a uma melhoria da condição de saúde da comunidade? Ou a afirmação do documento é conseqüência de uma tendência observada na operacionalização do ideário?

As falas dos atores acerca de sua concepção inicial sobre propósito $e$ estratégias do Programa UNI e os textos que embasaram a sua concepção $e$ a dos projetos nos levam a concluir que havia um postulado inicial dos formuladores do Programa. No tocante aos componentes "propósito" $e$ "estratégia", indicava a proposição de uma estratégia de "desenvolvimento sincrônico das organizações envolvidas" como o estabelecimento de limites dentro dos quais deveria ocorrer a "melhoria das condições de saúde e de vida da população".

Vimos, também, que o propósito inicial para os diretores de projetos já apontava para a "formação de profissionais de saúde" o que, claramente, determinou estratégias mais dirigidas, mesmo se considerarmos uma mesma categoria como "parceria". Observando as imagens mais atuais dos sujeitos sobre o propósito dos projetos e a partir de estudos recentes sobre o programa e os projetos, podemos concluir que a forma como foi desenvolvida a parceria nesses projetos condicionou e reduziu o propósito inicialmente colocado no ideário.

PARTICIPAÇÃO COMUNITÁRIA E CONTROLE SOCIAL: tudo o que é sólido, se desmancha e se refaz no caminhar

O terreno da "participação comunitária" pisado e trilhado pelos diversos grupos do Programa UNI (formuladores, diretores de projetos e avaliadores) foi tido como estando muito longe de se constituir como terreno sólido. Os conceitos "participação comunitária", "envolvimento comunitário" $e$ "controle social" aparecem indistintamente e, aparentemente, ao sabor das leituras mais recentes de cada um dos entrevistados. Mesmo assim, acreditamos ter delimitado o conceito com o qual cada grupo trabalhou, através da ação quotidiana revelada pelos atores.

O conceito de participação comunitária utilizado pelo Programa UNI é descontextualizado. Valla (1993, p.58), discutindo a participação popular sob o ponto de vista da educação em saúde, ressalta que o que está em jogo é um embate das diferentes forças da sociedade ao se falar de "participação popular". As várias definições existentes obedecem à concepção da sociedade $e$ aos interesses presentes nos grupos. Fala-se de participação comunitária em contextos concretos, com um olho em contextos sociais diversos. Ou seja, ela é historicamente construída e deve ser analisada como socialmente condicionada. A participação comunitária, em Botucatu, certamente não é igual à da Nicarágua.

O mesmo autor diferencia "participação popular" de "participação social", referindo-se a esta última como as múltiplas ações que diferentes forças 
sociais desenvolvem para poder influenciar as políticas públicas na área social (Valla, 1993).

Ao formular um programa que tentasse dar conta de fragilidades percebidas nos projetos que o antecederam, como a ausência de participação da comunidade nos projetos de Integração Docente-Assistencial, por exemplo, o Programa UNI estabelecia uma outra estratégia de construção de condições para a ocorrência da melhoria das condições de vida da população. Propunha a participação da comunidade como sujeito no seu próprio espaço, promovendo o cuidado com o ambiente e o auto-cuidado, mas também como sujeito nos espaços das outras organizações parceiras, ao participar de colegiados gestores dos serviços e de colegiados acadêmicos.

Como colocado pelo Entrevistado 6, a concepção teórica de participação comunitária é uma estratégia revolucionária para o contexto das organizações envolvidas nos Projetos UNI e os atores constatam um efetivo crescimento e fortalecimento das organizações comunitárias participantes dos Projetos. Alguns afirmam que esse fortalecimento da participação da comunidade é uma das grandes marcas no conjunto deles.

Por outro lado, considerando que o propósito dos Projetos foi mais focado na reformulação do modelo acadêmico, o que dizem os atores sobre a "impermeabilidade" da universidade à participação da comunidade nas discussões sobre a formação profissional é revelador do condicionamento imposto pela estrutura da universidade à estratégia proposta.

Portanto, também para a categoria "participação comunitária" ocorre uma idealização de seu desenvolvimento nos projetos, pois, por ser uma proposta revolucionária e contra-hegemônica, é geradora de conflitos por confrontar diferentes interesses. Por conta disso, a estratégia de participação acaba sendo reestruturada para níveis mais operacionais no desenvolvimento dos projetos, pouco ou nada efetivo nos níveis decisórios da universidade, também no seu próprio espaço, como revelado pelo não dito na fala dos atores: a ausência do estímulo ao autocuidado $e$ ao cuidado com o ambiente.

Esses conflitos passam, também, no Programa UNI, pela concepção de "comunidade" assumida pelos diferentes atores sociais. Pensando comunidade como uma parcela do corpo social, ou uma parte do todo na qual estão presentes as diversas forças em disputa, podemos afirmar que já existe um controle social - por parcelas da sociedade - sobre o serviço de saúde e sobre a universidade. Trata-se, portanto de ampliá-lo. Acreditamos que isto os Projetos UNI têm propiciado, trazendo "novos personagens para a cena", e tentando capacitá-los para as disputas. No entanto, o processo não é linear. Ele não se dá na mesma intensidade e não possui a mesma direcionalidade em todos os Projetos, porque está vinculado aos interesses e à potência dos diversos grupos.

As linhas de determinação e condicionamento que, segundo Testa, envolvem o poder como categoria central, já reconhecem e explicitam que os fatores positivos que estabelecem limites dentro dos quais deve ocorrer o fenômeno (determinação) e as forças negativas que impõem limites, fora dos quais não pode mais ocorrer o fenômeno (condicionamento), são impulsionadas pelos diversos poderes manejados pelos diversos grupos de 
atores constituídos. Desta forma, podemos verificar que, também a estratégia de Participação Comunitária, quando confrontada com a expectativa de um controle social sobre as organizações participantes, se vê condicionada pelos projetos dos grupos de atores com mais recursos envolvidos no processo.

\section{Organização no Programa UNI}

O componente organização no Projeto UNI, representado pela universidade, serviço de saúde e comunidade apresentou-se como o que mais condicionamento impôs sobre o propósito.

Para o serviço, a proposta de Sistemas Locais de Saúde - SILOS, enquanto modelo tecno-assistencial, não deixa de ser uma proposta que traz a perspectiva de ser o modelo para dar respostas à complexidade dos fenômenos determinantes das condições de vida e saúde da comunidade. Mesmo que a avaliação de resultados não seja um dos objetivos desta análise, não vimos que o SILOS tenha se estabelecido como modelo dos Projetos por nós investigados. Ele não se deu por diversos motivos, mas, dentre eles, podem ser levantados alguns relativos à própria potência $e$ efetividade do modelo proposto, outros relativos ao contexto das organizações e dos Projetos propriamente ditos.

No Brasil, o UNI surgiu em um momento de transição da transição: um momento em que o Movimento Sanitário, após conquistar a inclusão de suas bandeiras para a reforma do sistema de saúde na Constituição, pelo Sistema único de Saúde - SUS, enfrentava a forte reação de forças neoliberais contrárias. O UNI representava um reforço importante ao SUS. Vários autores já identificaram a coincidência do ideário com o SUS (Chompre, 1996; Gil, 1995; Cecilio, 1997). Acreditamos que essas coincidências se dêem por causa de fatores como: a) diretrizes colocadas pelo ideário, em geral, como a participação comunitária, e pelo modelo tecno-assistencial proposto - o SILOS -, como a descentralização e a regionalização, são, também, diretrizes do SUS; b) como já afirmamos, o SILOS representa um modelo hegemônico dentre os contra-hegemônicos, o que faz com que os gerentes, em parte, o assumam como discurso.

Cecilio (1997), discutindo a concepção de serviço de saúde no Programa UNI, observa que há uma insuficiência na definição do que são serviços ou que serviços de saúde interessam à população. Nessa discussão, o autor levanta o debate, já referido, que ocorre entre os diversos autores formuladores dos diferentes modelos tecno-assistenciais em saúde e filia o SILOS, em suas versões mais recentes, ao modelo programático que assume a epidemiologia como a lógica de organização dos serviços de saúde, contrapondo-a ao modelo clínico. Não reproduziremos, aqui, esse debate. Apenas abordaremos o que, nele, mais diretamente nos interessa e pode aclarar nosso objeto.

O modelo SILOS é uma proposta, fundamentalmente, de integração intersetorial, portanto, de resolução de problemas macroestruturais. Não negando a necessidade de integração macroestrutural, afirmamos que ela não é potente para lidar com os fatores ligados ao microespaço dos 
estabelecimentos de saúde e ao médio-espaço do sistema de saúde. Levantamos, em favor desta afirmação, os seguintes argumentos: a) os micro e médio-espaços da saúde são locus de disputas, muitas vezes, mais conflitivos que os espaços intersetoriais, porque pouco visíveis, e não adequadamente considerados; b) de acordo com Campos (apud CECILIO, 1997), é questionável a capacidade da programação para dar conta de todas as tarefas relacionadas à organização de um sistema de saúde; c) decorrente da anterior, as necessidades não-técnicas, sentidas pela população e trazidas aos serviços de saúde precisam ser adequadamente consideradas, se não, corre-se o risco de uma completa descrença da população nos estabelecimentos e no sistema de saúde; d) recentemente, tem ficado mais claro o discurso racionalizador do SILOS, como caminho para a retirada gradual do Estado da prestação à saúde, mais que como forma de potencializar as organizações envolvidas no setor.

Cecilio (1997) comenta que o UNI, na figura dos dirigentes dos Projetos que conheceu, acaba assumindo o SILOS como modelo tecno-assistencial em seu discurso e em sua prática. Na pesquisa aqui apresentada vimos, nas falas dos atores entrevistados, que o SILOS, enquanto modelo, acaba sendo lembrado por apenas um dos diretores. Independentemente do que se assume como discurso, vemos, na prática dos serviços, que os modelos propostos têm se tornado formas que engessam a criatividade dos trabalhadores e gerentes dos serviços $e$ as necessidades da população, tornando quase disfuncionais os ruídos de seu cotidiano, tanto relativos ao processo de trabalho, quanto à relação serviço-usuário.

Mais explicitamente, queremos dizer que os dirigentes não têm sabido aproveitar o que de potente existe nas diversas propostas, ao assumir um modelo e negar outros. Para minimizar e resolver alguns sofrimentos, a clínica tem se mostrado potente e tem credibilidade junto à população; para conhecer parte das necessidades das comunidades, a epidemiologia é importante e tem reconhecimento, inclusive da clínica, bem como a programação consegue dar conta de alguns dos chamados "grupos de risco"; para planejar e realocar alguns investimentos, a territorialização pode ser efetiva. Contudo, não podemos negar os conflitos e as disputas dos micropoderes presentes em diferentes espaços do sistema, como fator importante no momento de se operacionalizar a reorganização do setor, principalmente quando para ele convergem organizações como a universidade e a comunidade.

A universidade mostrou, no dia-a-dia dos Projetos, sua face conservadora e conflitiva, levando, certamente, os Projetos a concentrarem seus recursos e energias no trabalho de sensibilizar e suplantar as disputas internas, o que se constituiu em estratégias consumidoras de recursos $e$ sem eficácia, conforme observado por alguns dos seus diretores.

Não desconhecendo os diversos movimentos e contra-movimentos existentes internamente à universidade e no campo da Educação (ToralesPereira, 1997; Pires, 1997 e Schraiber, 1997), bem como os mesmos movimentos na relação da universidade com os processos e estruturas sociais de seus contextos (Wanderley, 1986; Giannotti, 1986; Cunha, 1980), queremos nos ater à discussão da coerência e potência de uma proposta de 
transformação paradigmática que se utiliza da universidade como sua mentora.

Nesse sentido, o que vimos nas falas dos atores do processo por nós entrevistados, foi uma difícil relação da universidade com as duas outras organizações e, internamente, entre os departamentos ou disciplinas. A justificativa da estabilidade desta organização, pouco afeita a mudanças bruscas por conta de suas decisões terem que ser colegiadas, como justificativa para que lhe fosse destinado mais poder na relação dos três, pode ter sido o desperdício de uma excelente oportunidade para criar potentes movimentos instituintes atravessadores das práticas instituídas nessa organização e nessa relação.

À comunidade foi aplicado o princípio, enunciado por diversos entrevistados, de compartilhar o discurso técnico, na suposição de que os conflitos se resolveriam pela razão iluminista e tecnocrática que suporta esse discurso. Como observaram alguns entrevistados, a comunidade continuou a reivindicar soluções afeitas ao "velho e hegemônico" modelo.

É interessante observar que alguns desses sujeitos, apesar de assumirem o discurso colocado na formulação do Programa, perceberam as contradições presentes em seus espaços concretos e foram à busca de novos referenciais, de forma mais ou menos sistematizada; outros continuaram a privilegiar as partes estáveis do sistema e "esconder" os conflitos de uma forma instrumental, ou seja, teorizando sobre os mesmos, mas se utilizando de estratégias que não possibilitavam seu afloramento.

Podemos, ainda, extrair dos enunciados desse grupo de atores uma concepção, ao nosso ver equivocada, que trata a organização comunidade como um espaço intrinsecamente democrático. Como outras organizações $e$ instituições, ela pode ser construída de forma democrática, mas isso não lhe é inerente. Pelo contrário, por sua própria definição, é um espaço atravessado por inúmeros grupos com interesses e desejos muito diversos $e$ contraditórios, o que, em uma sociedade de tradições autoritárias e populistas como a nossa, não se autoriza essa pressuposição, no mínimo, ingênua.

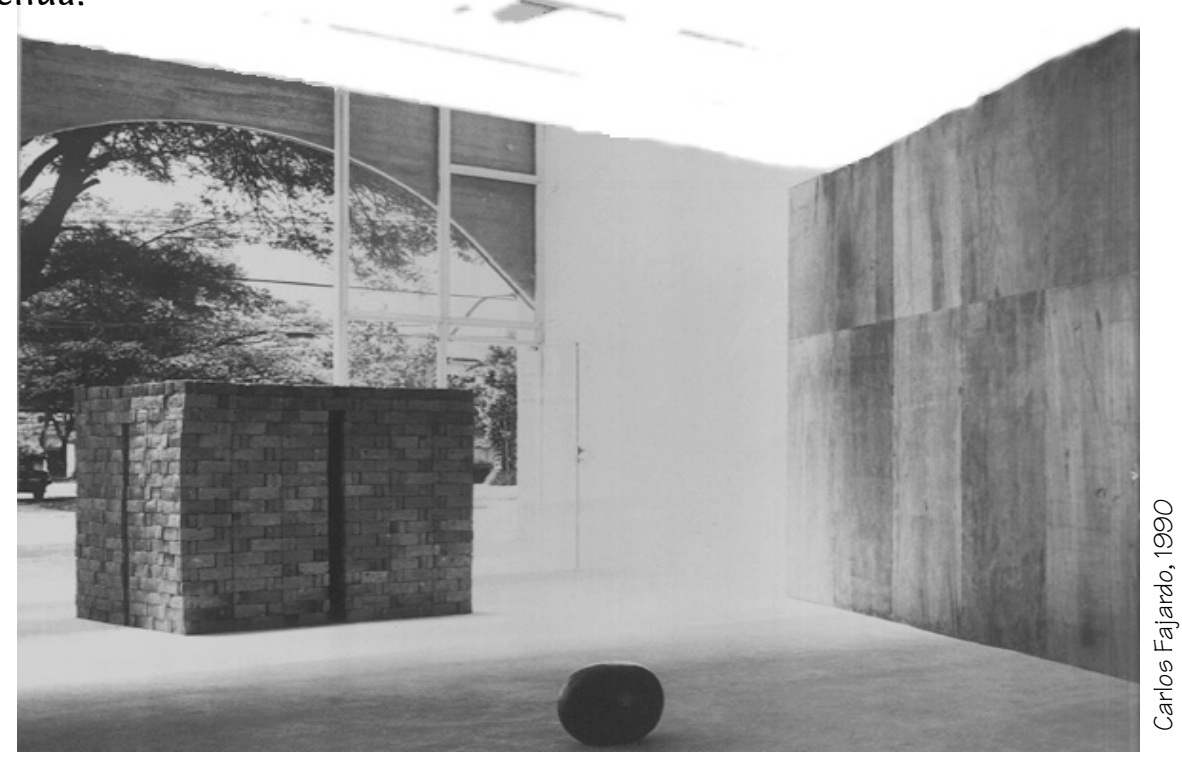


Acreditamos, portanto, que o Programa UNI postulava uma linha de determinação dos propósitos e do método sobre a organização, ou seja, seus formuladores contavam que seus propósitos e métodos encontrariam, nessas organizações, possibilidades para o seu desenvolvimento, ou que, no mínimo, as resistências não seriam tão intensas.

Ao ser operacionalizado, nos diferentes Projetos, o Programa UNI iniciou com três diferentes propostas, embora interligadas. Primeiro, a melhoria das condições de saúde e de vida da população, que pressupunha como estratégia o avanço gradual e em parceria das três organizações envolvidas; segundo, a melhoria do sistema de saúde, pela construção de um novo modelo assistencial, de um novo modelo formador de profissionais e da participação comunitária nessa construção; terceiro, a produção de mudanças no modelo formador de profissionais da área da saúde, utilizando a parceria com os serviços de saúde e com a comunidade como estratégia.

Devemos, também, citar o reconhecimento explícito que os atores fazem às inegáveis forças positivas operadas pelos propósitos nos microespaços organizacionais dos Projetos, como as que se seguem: a) o apoio decisivo para "desencantar" propostas de reforma curricular em algumas universidades; b) o movimento por capacitação pedagógica dos professores das universidades; c) a presença de Conselhos Tripartites ( academia, serviço e comunidade) decidindo atividades da universidade, mesmo que de forma localizada; d) o despertar de profissões não tradicionais do campo da saúde, como portadoras de novas formas de olhar a relação da equipe de saúde; e) a reorganização dos sistemas de referência e contra-referência nos sistemas de saúde; f) a organização de sistemas de informação e de apoio logístico pela informatização das redes de serviços de saúde; g) a melhoria da rede de serviços de saúde, com a construção e ampliação das unidades e compra de equipamentos; h) a capacitação técnica dos profissionais dos serviços; i) a ampliação dos espaços de participação da comunidade nos serviços de saúde, com a criação de Conselhos Locais; j) a reorganização dos movimentos comunitários, fazendo ressurgir novos/velhos personagens nas cenas de disputas; 1) a ampliação da efetiva participação desses movimentos nos espaços do serviço e da universidade.

\section{Conclusões}

Durante nossa análise, pudemos observar que, na verdade, o processo de construção e reconstrução dos propósitos e métodos pelos Projetos foi se dando na prática concreta das organizações e das relações sociais, atravessadas por micropoderes e por grupos de indivíduos atuando como "máquinas desejantes" (Merhy, 1997, p.88) nas relações de determinação e condicionamento entre os componentes do postulado de coerência e no nível dos Projetos.

Havia, aparentemente, uma coerência entre propósito, método e organização na formulação do ideário, sugerindo determinações dos primeiros para este último e de propósito para método. Porém, durante a análise, estas linhas não se configuraram como reais. 


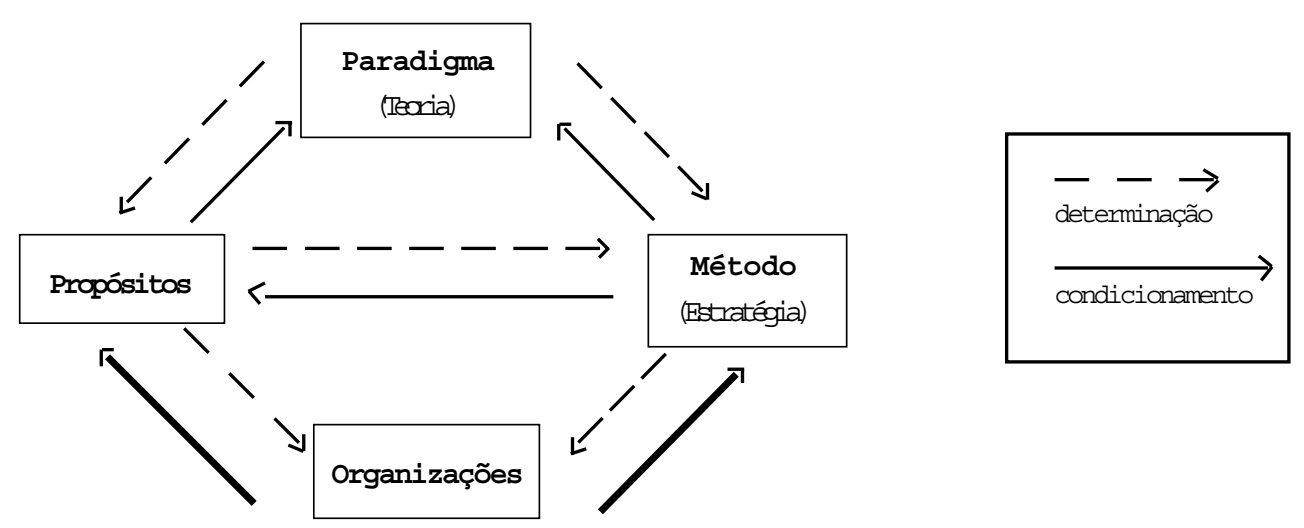

Figura 4 - Coerência no espaço concreto de Serviços e Comunidade. (Fonte: LINS, 1997)

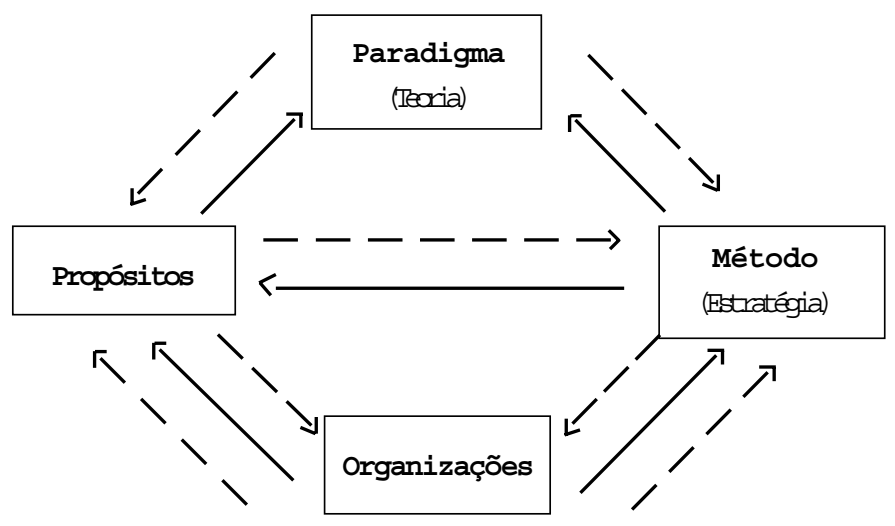

Figura 5 - Coerência no espaço concreto da Universidade.

(Fonte: LINS, 1997)

O que observamos é que as linhas de determinação e condicionamento são diferentes para as três organizações envolvidas. No espaço concreto de operacionalização dos Projetos, os propósitos são fortemente condicionados pelas organizações Serviços e Comunidade, embora eles as determinem (Figura 4). No caso da Universidade, ocorre uma dupla determinação no sentido de propósitos para organização e, desta, para aqueles; a universidade também condiciona, fortemente, os propósitos do Programa (Figura 5).

Identificamos vários fatores que podem explicar os sentidos das linhas de condicionamento e determinação das organizações sobre os propósitos $e$ métodos do Programa UNI.

No caso da Comunidade, podemos ressaltar fatores limitantes, como: a assimetria dos saberes entre as organizações; as disputas políticas entre os diversos grupos; as diferenças na participação; o atraso conceitual sobre participação; o descrédito nos modelos assistenciais.

Nos Serviços, identificamos como fatores condicionantes: a crise paradigmática, organizacional, ética e financeira do SUS; a resistência das 
corporações do setor; a hegemonia do modelo médico-liberal; a baixa credibilidade junto às duas outras organizações; a desorganização $e$ desestruturação dos movimentos mais combativos do setor.

A Universidade, enquanto organização, se diferencia das duas outras por apresentar, além das linhas de condicionamento, outras de determinação. Como fatores limitantes aos propósitos e métodos do Programa, podemos relacionar: os diversos e potentes micropoderes existentes, representados pelos departamentos e pelas disciplinas; os interesses corporativos existentes nesses espaços; a cultura da predominância do saber aí produzido, sobre os demais saberes; a hegemonia do modelo flexneriano de formação.

Já como fatores determinantes que partem dessa organização, podemos identificar, principalmente, sua estrutura mais conservadora e estável $e$ a própria atribuição de poder à Universidade, pelo Programa, ao colocá-la como protagonista da parceria, destinando-lhe, formalmente, tal papel e a guarda dos recursos financeiros destinados a cada Projeto. Desta forma, a Universidade capturou propósitos e métodos dos Projetos, reinterpretandoos para seu espaço e finalidade.

Mesmo levando em conta que a formulação inicial do Programa não tenha considerado adequadamente as linhas de determinação $e$ condicionamento entre os três componentes do postulado, acreditamos não ter havido uma falência da proposta, provavelmente porque essas coerências, como vimos, foram sendo construídas em cada espaço concreto e, também, por conta das inúmeras forças positivas operadas pelo ideário no espaço dos projetos.

Há que se ressaltar que o Ensino, a Saúde e porções da Sociedade, como instituições enunciantes das opções concretizadas pelas organizações participantes do Programa UNI, têm um peso determinante sobre elas, o que faz com que seja criada uma linha de condicionamento muito forte das organizações sobre os propósitos, ou mesmo de determinação no mesmo sentido, como pudemos verificar na relação da Universidade com os propósitos e métodos dos Projetos UNI. Acreditamos que esta organização passou, na realidade dos Projetos, a determinar os seus propósitos.

Portanto, em nossa visão, a observação da relação de coerência entre propósitos, métodos e organização é condição necessária para a efetividade de projetos ou programas, mas não suficiente, havendo outros fatores intervenientes, como: a) a potência do paradigma explicativo adotado, diante da complexidade do objeto; b) a existência da relação dialética que se estabelece entre objeto e sujeito, verdadeira construtora das linhas de determinação e condicionamento.

Concluímos pela necessidade premente de se investigar instrumentos de avaliação que, no cotidiano dos projetos, possam captar as linhas de determinação e condicionamento presentes, suas direcionalidades e possam alertar para a insuficiência contextual das teorias explicativas, possibilitando a mobilização de novos e mais adequados referenciais.

\section{Referências bibliográficas}

BAREMBLITT, G.F. Compêndio de análise institucional e outras correntes: teoria e prática. 3.ed. Rio de Janeiro: Rosa dos Tempos, 1996.

CECILIO, L.C.O. Uma reflexão sobre o desenvolvimento dos serviços de saúde no Programa UNI da Fundação Kellogg. São Paulo, 1997.(mimeo).

CHOMPRE, R. A enfermagem nos projetos UNI: contribuição para a redefinição de um novo projeto político para a enfermagem brasileira. São Paulo, 1996. Tese (Doutorado). Escola de Enfermagem da 
Universidade de São Paulo, 1996.

CUNHA, L. A. A universidade temporã. 2. ed. Rio de Janeiro: Francisco Alves, 1980.

FERREIRA, A.B.H. Novo Dicionário da Língua Portuguesa. 15. ed. Rio de Janeiro: Nova Fronteira, 1991.

FETTERMAN, D.M. Empowerment evaluation and accreditation in higher education. In: CHELIMSKY, E. e SHADISH, W.R. Evaluation for the 21st century: a handbook. California: Sage Publications, 1997.

GIL, C.R.R. Avaliação de projetos: análise do Projeto UNI - Londrina. Avaliação como instrumento de ação. Londrina, 1995. Dissertação (Mestrado). Universidade Estadual de Londrina, 1995.

GILLES, T.R. Dicionário de Filosofia. São Paulo: EPU, 1993.

KISIL, M., CHAVES, M. Introdução ao Programa UNI. In: FUNDAÇÃO W. K. KELLOGG. Programa UNI: uma nova iniciativa na educação dos profissionais da saúde. Batlle Creek, EUA, 1994.

LINS, A.M. O programa Uni da Fundação Kellogg no Brasil: uma avaliação a partir do postulado de coerência de Mário Testa. Campinas, 1997. Dissertação (Mestrado). Universidade Estadual de Campinas, 1997.

MERHY, E.E. Em busca do tempo perdido: a micropolítica do trabalho vivo em saúde. In: MERHY, E.E. e ONOCKO, R. (orgs.) Agir em saúde - um desafio para o público. São Paulo: HUCITEC, 1997.

MINAYO, M.C.S. O desafio do conhecimento. Pesquisa qualitativa em saúde. 2. ed. São Paulo: HUCITEC/Rio de Janeiro: ABRASCO, 1993.

PIRES, M. F.C. O materialismo histórico-dialético e a educação. Interface Comunic, Saúde, Educ, v.1, n.1, p. 83-94, 1997.

PROGRAMA UNI. Propuesta de evaluación del conjunto de proyectos (Cluster). Dimensiones y subdimensiones. São Paulo: Fundação W. K. Kellogg, 1993.

PROGRAMA UNI. Evaluacion del conjunto de proyectos UNI. Cluster Uni Informe del Primer Período. São Paulo: Fundação W. K. Kellogg, 1995.

PROGRAMA UNI. Evaluación del cluster de proyectos. Actualización: precisiones conceptuales acerca del modelo evaluativo. São Paulo: Fundação W. K. Kellogg, 1996.

SADER, E. Quando novos personagens entraram em cena. Experiências e lutas dos trabalhadores da Grande São Paulo:1970-1980. 2. ed. São Paulo: Paz e Terra, 1991.

SCHRAIBER, L. B. No encontro da técnica com a ética: o exercício de julgar e decidir no cotidiano de trabalho em Medicina. Interface -Comunic, Saúde, Educ, v.1, n.1, p.123- 40, 1997.

SILVA JUNIOR, A.G. Modelos tecno-assistenciais em saúde: $O$ debate no campo da saúde coletiva. Rio de Janeiro, 1996. Tese (Doutorado). Escola Nacional de Saúde Pública, Fiocruz, 1996.

TESTA, M. Tendências em planejamento. In Porto Alegre: Artes Médicas, 1992. Pensar em Saúde.

TORALLES-PEREIRA, M.L. Notas sobre a educação na transição para um novo paradigma. Interface -Comunic, Saúde, Educ, v.1, n.1, p.51-68, 1997.

VALLA, V.V. Participação popular e saúde: a questão da capacitação técnica no Brasil. In: VALLA, V.V. e STOTZ, E.N. (orgs.) Participação popular, educação e saúde: teoria e prática. Rio de Janeiro: Relume Dumará, 1993.

WANDERLEY, L.E.W. O que é universidade. 6. ed. Rio de Janeiro: Brasiliense, 1986.

WORTHEN, B.et al. Program evaluation, alternative approaches and practical guidelines. 2. ed. New York: Longman, 1997. 


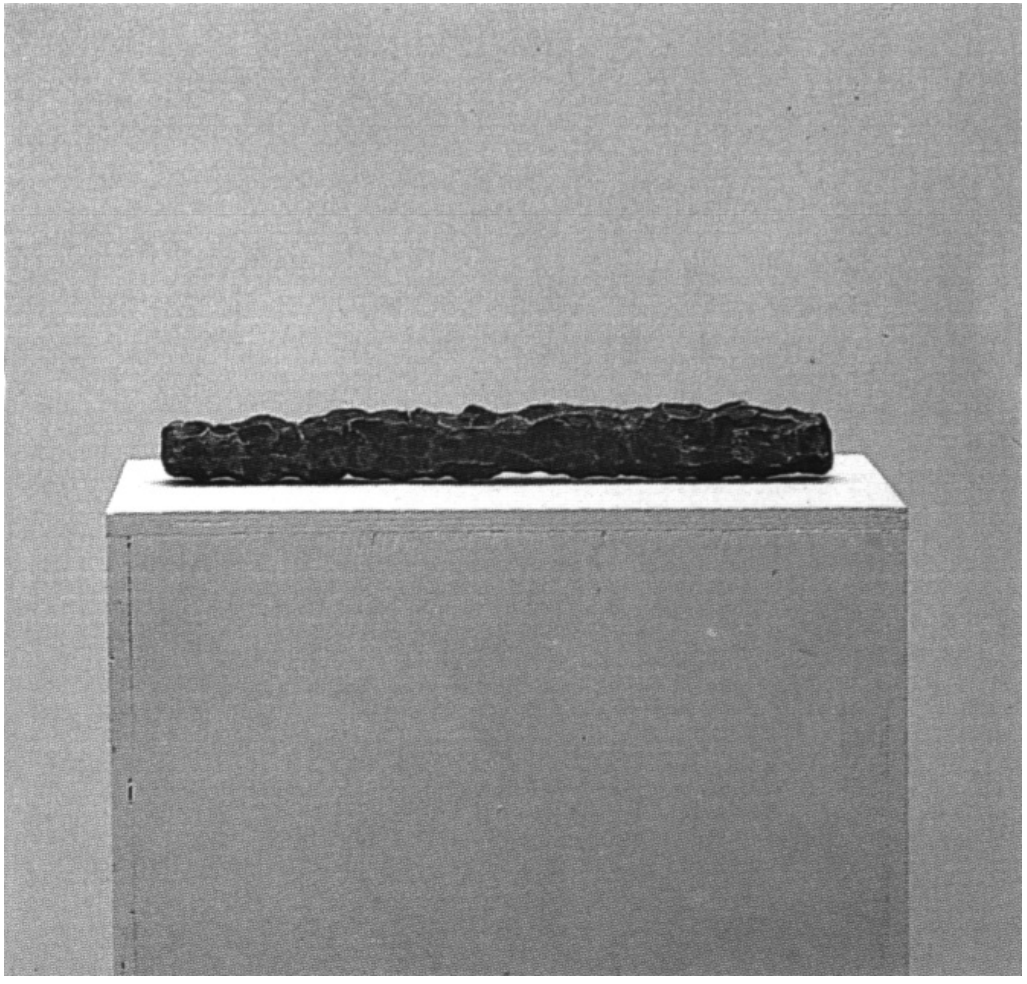

Bronze, Carlos Fajardo, 1992

106 Interface _ Comunic, Saúde, Educ 3 